\title{
A Study of Prescription Pattern of Antibiotics in Pediatric In-Patients of Mc-Gann Teaching Hospital Shivamogga Institute of Medical Sciences (SIMS), Shivamogga, Karnataka.
}

\author{
Dr. Shivaleela, Dr. K.Jagadeesh, Dr. Shreenivas. Revankar, Dr Vedavathi H, \\ Dr. S.Nagaraja.Prasad, Dr Chidanand K N, Dr Jean L M \\ Department of Pharmacology, Shivamogga Institute of Medical Sciences, Sagar Road, Shivamoga-577201. \\ Corresponding author Dr Vedavathi $H$
}

\begin{abstract}
Introduction: Rational antibiotic prescription is very important to prevent antimicrobial resistance. So the present study was conducted to know the rational use of drug in paediatric in-patient of Mc-Gann teaching hospital, SIMS, Shivamogga.

Material and Methods: A retrospective study of 2months duration was undertaken during May-June of 2013. A total number of 100 patients case sheets were utilized for our study from paediatric in-patients department of Mc-Gann teaching hospital. Patients were included with history of various infections. The data were analysed by using SPSS.

Result and Conclusion: The mean age of paediatric patient was 5.8. The average number of drugs per encounter was 4.26. The average number of antibiotic per patient was 2.13. In present study antibiotic were $50 \%$ of total drugs prescribed and $98.1 \%$ of antibiotics were prescribed from the WHO list of essential medicine, 2013. Most common prevalence of disease among study patients sample was acute gastroenteritis. The most commonly prescribed antibiotics were Cefixime and Gentamicin. In present study $47.59 \%$ of antibiotics were prescribed in generic name. Most commonly preferred route for antibiotic administration was intravenous route $(93 \%)$ and next common was oral route.

The present study on antibiotic prescription pattern reveals prescribing pattern was not rational, as there is polypharmacy, less use of generic drugs, over use and inappropriate use of antibiotics, and excessive parenteral use of antibiotics administration. But prescription pattern was rational regarding adhering to WHO list of essential medicine. Strict adherence to the antibiotic prescription policy can significantly overcome the overuse of antibiotics and reduce the development of resistance to antibiotics.
\end{abstract}

Key Words: Paediatric, Antibiotics, Rational, Prescription pattern, Generic

\section{Introduction}

Pediatrics is the specialty of medical science concerned with the physical, mental and social health of children from birth to young adulthood ${ }^{1}$. We live in world which is heavily populated by microorganisms of astonishing diversity. In this environment the paediatric group populations are commonly affected by various infectious diseases. Antibiotics are commonly prescribed to treat various infectious condition ${ }^{2,3}$. Several studies reported that $50 \%$ to $85 \%$ of children receive antibiotics in developed and developing countries ${ }^{4}$. Rational antibiotic prescription is very important to avoid multiple drug resistance, treatment failure, non-compliance and increase in cost of treatment ${ }^{5}$. Rational use of drug method can be done by following six steps such as-1)defining the patients problems(diagnosis), 2)defining effective and safe treatment(drugs and nondrug options), 3)selecting appropriate drug, dosage, duration, 4) writing a legible prescription, 5)giving patient adequate information and 6)proper planning to evaluate treatment response ${ }^{6}$.

Emergence of antibiotic resistance is a worldwide phenomenon and it is due to over use of antibiotics ${ }^{6}$. Increased self prescribing, poor choice of antibiotics, not following routine susceptibility testing and inadequate surveillance are other factors contributing to development of antibiotic resistance ${ }^{6,7}$. Dr.M.Ipp study showed that antibiotics are unnecessarily prescribed for viral infections such as common cold ${ }^{8}$. Strategies should be made to optimize antibiotic use and this will minimize the antibiotic resistance. Following the strategy developed by WHO in a collaborative work with international network for rational use of drug (INRUD) $)^{8,9}$ can detect the problems in drug prescribing such as polypharmacy, inclination for branded products, over use of antibiotics or injections and prescribing out of formulary or essential drug list. As prescription pattern analysis is continuous processes, the present study was done, to know the rational use of drug in paediatric in-patients of Mc-Gann teaching hospital, SIMS, Shimoga. 


\section{Materials And Methodology}

A retrospective study of 2months duration was undertaken during May-June of 2013. A total number of 100 patients case sheets were utilized for study from pediatric in-patients department of Mc-Gann teaching hospital attached to SIMS, Shimoga. Patients were included in study with age between 1month to 13years with diagnosis of respiratory, gastrointestinal, urinary tract and other infections. Neonates were excluded. Randomization was done by selecting alternative case sheets. The data's were collected in proforma, which includes name, age, gender, diagnosis, number of drugs prescribed, number of antibiotics prescribed with dose and routes of drug administration and also condition of patient on discharge were recorded. Intravenous fluids, blood transfusion and nutritional preparations were not included in the study. Source of data was collected from patient's case sheets obtained from record section. Ethical clearance was taken from institutional ethical committee.

Drugs data on the utilization of antibiotics and patient's data were computed using MS Excel and statistical analysis was done by using SPSS (Statistical package for the social sciences). The results were expressed as percentages or as mean \pm standard deviation (SD).

\section{Results}

The mean age of pediatric in-patient was 5.8(years). More number of patients were belong to 1-5years age group (47\%), next in 5-13years group (43\%) and less number in 1 month -1 year group $(10 \%)$. The male patients accounted for admitted were 54percent, whereas the female patients were accounted for admitted 46percent(Table no 1).

Table no1: Paediatric in patient characteristics

\begin{tabular}{|l|c|}
\hline Parameters & Percentage (\%) \\
\hline Age & 10 \\
\hline 1month - 1year & 47 \\
\hline 1-5year & 43 \\
\hline 5-13year & $67.89 \pm 40$ \\
\hline Age (mean in months ) & 54 \\
\hline Gender & 46 \\
\hline Male & \\
\hline Female & \\
\hline
\end{tabular}

The average number of drugs per encounter was 4.26. All patients were exposed to more than one drug. The average number of antibiotic per patient was 2.13 . Multiple antibiotics were prescribed in $92 \%$ patients, only one antibiotic was prescribed in $8 \%$ patients, two antibiotics in $76 \%$ patients, three antibiotics in $12 \%$ patients, four antibiotics in $3 \%$ patients and five antibiotics in one percent.

In present study antibiotics were prescribed $50 \%$ of total drugs. In present study $98.1 \%$ of drugs were prescribed from the WHO list of essential medicine, 2013.

Table no2: Paediatric in-patients exposure to drugs and antibiotic

\begin{tabular}{|l|l|l|l|}
\hline Drugs /patient & $\% \quad$ (No ) & Antibiotic/patient & $\%$ (No) \\
\hline 1 & 0 & 1 & 8 \\
\hline 2 & 3 & 2 & 76 \\
\hline 3 & 24 & 3 & 12 \\
\hline 4 & 39 & 4 & 3 \\
\hline 5 & 18 & 5 & 1 \\
\hline 6 & 12 & & \\
\hline 7 & 2 & & \\
\hline 8 & 2 & & \\
\hline Range & $1-8$ & RANGE & $1-5$ \\
\hline Mean \pm SD & $3.33 \pm 2.11$ & MEAN \pm SD & $2.13 \pm 0.62$ \\
\hline
\end{tabular}

More than one antibiotic was prescribed for patients with diagnosis of acute gastroenteritis (GE), lower respiratory tract infection (LRTI), viral fever, upper respiratory tract infection (URTI), pneumonia, enteric fever and dengue fever. Only one antibiotic was prescribed in infective hepatitis.

Most common prevalence of disease among study patients sample was acute gastroenteritis (20\%). Enteric fever more was common in above 5years of children (75\%). LRTI (55\%) and URTI (100\%) were more common in age groups between 1-5years of children (Table no 3). 
Table no3: Diagnosis pattern in different age groups

\begin{tabular}{|l|l|l|l|l|}
\hline DIAGNOSIS & 1 month-1yr & $1-5 \mathrm{yr}$ & $5-13 \mathrm{yr}$ & Total \\
\hline Acute GE & 3 & 7 & 10 & 20 \\
\hline LRTI & 2 & 5 & 2 & 9 \\
\hline Viral fever & 0 & 3 & 5 & 8 \\
\hline URTI & 0 & 6 & 0 & 6 \\
\hline Pneumonia & 0 & 5 & 1 & 6 \\
\hline Enteric fever & 0 & 1 & 9 & 10 \\
\hline Dengue fever & 0 & 4 & 12 & 16 \\
\hline OTHERS & 4 & 13 & 8 & 25 \\
\hline
\end{tabular}

Acute GE- Acute gastroenteritis, LRTI-Lower respiratory tract infection, URTI- Upper respiratory tract infection, others- infective hepatitis, appendicitis etc.

Cefixime was most commonly prescribed in acute GE followed by gentamicin and other antibiotics. Gentamicin (37.98\%) commonly prescribed among all antibiotics and next most commonly prescribed was Cefixime $(33.17 \%)$ (Table no 4).

Table no4: Frequency (\%) of individual antibiotic for specific diagnosis

\begin{tabular}{|c|c|c|c|c|c|c|c|c|}
\hline Diagnosis & Cefixime & Gentamicin & $\begin{array}{l}\text { Ciprofloxa } \\
\text { cin }\end{array}$ & $\begin{array}{l}\text { Ceftriax } \\
\text { one }\end{array}$ & Amikacin & BP & $\begin{array}{l}\text { Metronida } \\
\text { zole }\end{array}$ & Others \\
\hline $\begin{array}{l}\text { AGE } \\
\%\end{array}$ & $\begin{array}{l}17 \\
(45)\end{array}$ & $\begin{array}{l}16 \\
(42)\end{array}$ & $\begin{array}{l}1 \\
(3)\end{array}$ & 0 & 0 & 0 & $\begin{array}{l}4 \\
(10)\end{array}$ & 0 \\
\hline $\begin{array}{l}\text { LRTI } \\
\%\end{array}$ & $\begin{array}{l}9 \\
(47)\end{array}$ & $\begin{array}{l}8 \\
(42)\end{array}$ & 0 & 0 & 0 & 0 & 0 & $\begin{array}{l}4 \\
(11)\end{array}$ \\
\hline $\begin{array}{l}\text { Pneumonia } \\
\%\end{array}$ & $\begin{array}{l}3 \\
(25)\end{array}$ & $\begin{array}{l}5 \\
(42)\end{array}$ & $\begin{array}{l}1 \\
(8)\end{array}$ & $\begin{array}{l}2 \\
(17)\end{array}$ & 0 & 0 & 0 & $\begin{array}{l}4 \\
(8)\end{array}$ \\
\hline $\begin{array}{l}\text { Viral fever } \\
\%\end{array}$ & $\begin{array}{l}7 \\
(44) \\
\end{array}$ & $\begin{array}{l}8 \\
(50) \\
\end{array}$ & 0 & $\begin{array}{l}1 \\
(6) \\
\end{array}$ & 0 & 0 & 0 & 2 \\
\hline $\begin{array}{l}\text { URTI } \\
\%\end{array}$ & $\begin{array}{l}6 \\
(50) \\
\end{array}$ & $\begin{array}{l}6 \\
(50) \\
\end{array}$ & 0 & 0 & 0 & 0 & 0 & 4 \\
\hline $\begin{array}{l}\text { Enteric fever } \\
\%\end{array}$ & $\begin{array}{l}4 \\
(15)\end{array}$ & $\begin{array}{l}9 \\
(33) \\
\end{array}$ & $\begin{array}{l}5 \\
(18) \\
\end{array}$ & $\begin{array}{l}8 \\
(30) \\
\end{array}$ & 0 & 0 & 0 & $\begin{array}{l}1 \\
(4)\end{array}$ \\
\hline $\begin{array}{l}\text { Dengue fever } \\
\%\end{array}$ & $\begin{array}{l}11 \\
(38) \\
\end{array}$ & $\begin{array}{l}13 \\
(45) \\
\end{array}$ & 0 & $\begin{array}{l}3 \\
(11)\end{array}$ & 0 & 0 & $\begin{array}{l}1 \\
(3)\end{array}$ & $\begin{array}{l}3 \\
(3) \\
\end{array}$ \\
\hline $\begin{array}{l}\text { Others } \\
\%\end{array}$ & $\begin{array}{l}12 \\
(31)\end{array}$ & $\begin{array}{l}14 \\
(36)\end{array}$ & 2 & $\begin{array}{l}8 \\
(21)\end{array}$ & $\begin{array}{l}1 \\
(2)\end{array}$ & $\begin{array}{l}2 \\
(2)\end{array}$ & 1 & $\begin{array}{l}7 \\
(8)\end{array}$ \\
\hline
\end{tabular}

$\mathrm{AGE}=$ Acute gastroenteritis, LRTI $=$ Lower respiratory tract infection, URTI $=$ Upper respiratory tract infection, others=infective hepatitis, appendicitis. $\mathrm{BP}=$ Benzathine penicillin, others= erythromycin, chloroquine, ofloxacin, meropenam etc.

Figure no 1: Number of antibiotics used in prescription

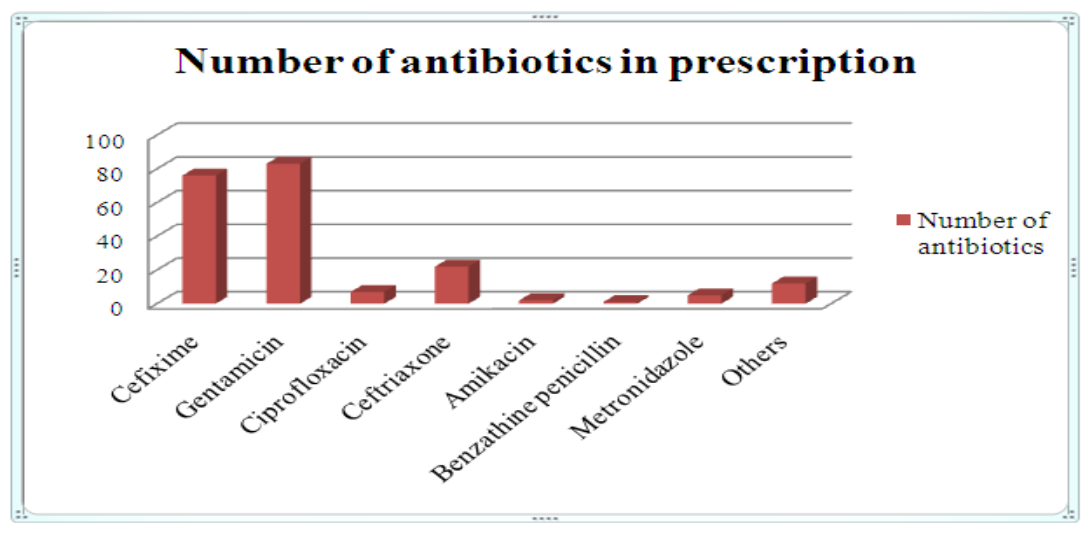

In present study $47.59 \%$ of antibiotics were prescribed in generic name. In this study 201(94.36\%) antibiotics of the total antibiotics were administered by parenteral route (intravenous and intramuscular routes) followed by $12(5.6 \%)$ antibiotics by oral route. 
Figure no 2: Route of administration of antibiotics

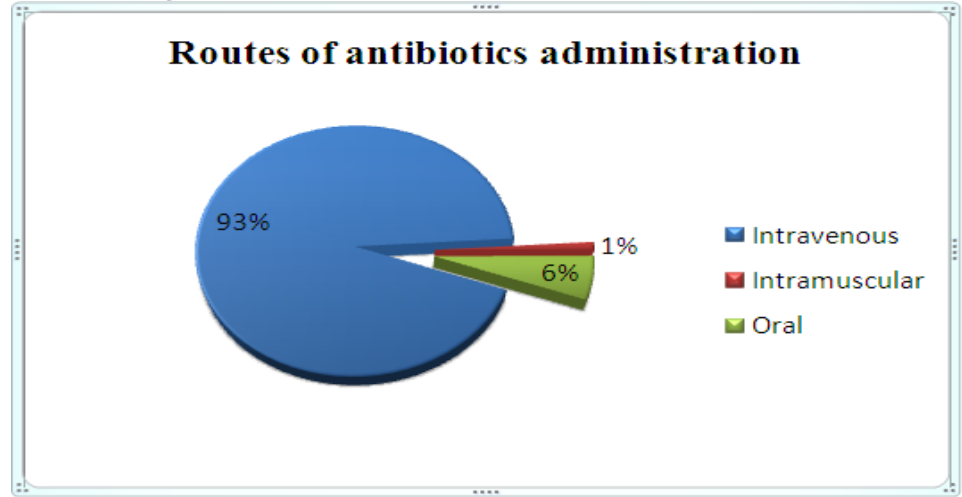

In oral route dosage forms: $51.5 \%$ of patients were given syrup type dosage form and $48.4 \%$ of patients were given tablet type dosage form.

For 100 patients infectious diseases were clinically diagnosed and treated with antibiotics, but specimens were taken for culture in only 25 cases to identify the organisms. Culture results were not mentioned in case sheets. Adverse drug reaction were not recorded in any of the case sheets.

\section{Discussion}

The present study was carried out in 100 prescriptions randomly selected pediatric in-patients case sheets from record section of Mc-Gann teaching hospital, SIMS, Shivamogga.

The more number of paediatric patients belongs to age group 1-5years (47\%) and next in 513 years $(43 \%)$. This indicates more chances of infections in 1-5years age group. Choudhury DK study shows more patients belong to $5-12$ years ${ }^{11}$.

The male patients(54\%) were more compared to female(46\%). The same findings were seen in other studies like Choudhury DK, Kanish et al study ${ }^{11,12}$.

The average number of drugs prescribed per encounter was 4.26. It could be due to in-patients nature of the study.In Arute JE study and Triruthopu NS study shows average number of drugs per prescription was $4.54 \pm 1.71$ and 4.56 respectively and more than present study ${ }^{13,}{ }^{14}$. The WHO recommends that the average number of drugs per prescription should be less than two ${ }^{15}$. In present study this number is more than two, so it indicates polypharmacy ${ }^{15}$. The average number of drugs per prescription value should be low as possible to prevent the unfavorable outcomes of polypharmacy such as increased risk of drug interactions, increased cost of therapy, non-compliance and emergence of resistance in case of use of antimicrobials.

The average number of antibiotics prescribed per patient was $2.14 \pm 0.62$ and this number is more compared to Choudhury DK, Kanish et al and Arute JE studies ${ }^{11,12,13}$.

In present study $50 \%$ of antibiotic were prescribed and this percentage is less compared to Kanish et al study and more compared to Shankar et al study ${ }^{12,16}$.

The multiple antibiotics were prescribed in $92 \%$ patients and this is more compared to Choudhury DK study $(29 \%)^{11}$. This indicates severity of disease or failure of treatment with one antibiotic. In present study only one antibiotic was prescribed in $8 \%$ of patients and five antibiotics were prescribed in one percent of patient. In Palikhe N study $79 \%$ of patients received multiple of antibiotics and $21 \%$ of patients received only one antibiotic $^{6}$. In present study percentage of multiple antibiotics prescribed is more and this indicates delay of diagnosis or selection of inappropriate antibiotic.

Cefixime and Gentamicin both drugs were prescribed in most of the infectious diseases like acute GE, pneumonia, URTI, bronchiolitis, dengue fever. Enteric fever was generally treated with Ceftriaxone and only one antibiotic was prescribed in infective hepatitis.

Most common prevalence of disease among the study was acute GE and it is treated commonly by Cefixime and Gentamicin. In present study most commonly prescribed antibiotic was third generation cephalosporin and this result was comparable with other studies like Choudhury DK and Kanish et al and Van Houten MA study ${ }^{11,12,17 .}$

Most of the antibiotic prescriptions were based on clinical diagnosis, not on culture report. In $25 \%$ of cases antibiotics were prescribed based on culture report and in most of case sheets culture results were not mentioned. It is important to obtain proper specimen, examination and culture for selection of antibiotics. This can prevent development of antibiotic resistance, reduces the side effects of drugs and also decrease the cost of treatment. This will help for selection of appropriate antibiotics ${ }^{18}$.

In present study $98.1 \%$ of drugs were prescribed from the WHO list of essential medicine, 2013, and this is more compared to Kanish et al study ${ }^{12,19}$. Drug prescription from essential list of medicine is beneficial in terms of cost effectiveness and safety of the drugs ${ }^{11}$. 
In present study $47.59 \%$ of generic name antibiotics were prescribed, this percentage is less compared to Kanish et al study $(58 \%)^{12}$.

In present study $94.36 \%$ of antibiotics were administered by parenteral route and $5.6 \%$ by oral route. Parenteral route is expensive and associated with other problems ${ }^{20}$. WHO recommends lesser use of injection as it helpful in reducing the cost of treatment and its disadvantages ${ }^{11}$. But some factors facilitate the use this route.

In oral dosage forms the most commonly used dosage form was syrup. Children are comfortable with the dosage form like syrup and drops compared to tablets and capsules. It increases compliance and helps in completing the treatment regimen.

Recording adverse drug reaction is very important to evaluate the safety of drugs. In no case sheets adverse drug reactions were reported and it may be there is no proper documentation done.

In present study most common antibiotics prescribed was Cefixime belongs to third generation cephalosporin. Next most commonly prescribed was Gentamicin belongs to aminoglycoside. Ceftriaxone was also prescribed as third most common drug.

\section{Conclusion}

In present study antibiotic prescription pattern was not rational as there is polypharmacy, less use of generic drugs, overuse and inappropriate use of antibiotics, excessive parenteral use of antibiotics administration. Prescription pattern was rational regarding adhering to national formulary list of drugs, 2013. As the resistance of antibiotics is increasing, so they should be selected based on culture report and limited use of antibiotics should be done in patients especially in paediatrics.

Limitation of present study was sample size was less and done in single hospital, so if sample size is more and taken from different hospitals then study will be more effective.

Rational use of drugs is largely influenced by knowledge, attitude and its importance has to be emphasized at the earliest. This should be included in medical education to have long term beneficial effects.

Strict antibiotic prescribing policy significantly overcome the overuse of antibiotics and reduces the development of resistance to antibiotics. Prescription pattern analysis or auditing types of studies are to be conducted on large scale in different health sectors then study will be more effective and help in making local policy for antibiotics prescription in paediatric and also in other specialties.

\section{References}

[1]. Definition of a paediatric according to American academy of paediatrics (AAP). www.pedjobs.org/pdf/AAP.

[2]. Sanz EJ, Bergman U, Dahlstorm M. Paediatric drug prescribing. A comparison of Tenerife (canary Islands, Spain) and Sweden. Eur J clinpharmacol, 1989; 37(1):65-68.

[3]. Summers RS, Summers B. Drug prescribing in paediatrics at a teaching hospital serving a developing community. Ann Trop paediatr 1986; 6:129-133.

[4]. Paluk E, Katzentein D, Frankish CJ, Herbert CP, Miler R, Speert D et al. Prescription practices and attitudes toward giving children antibiotics. Can Fam Physician 2001;47:521-7.

[5]. Gopalakrishnan Sekharan, Ganeshkumar Parasuraman, Katta Ajitha. Assessment of prescribing practices among urban and rural general practitioners in Tamil Nadu. Indian journal of Pharmacology,2013;45(3);252-257.

[6]. Palikhe, N. Prescribing Pattern of Antibiotics in Paediatric Hospital of Kathmandu Valley. Journal of Nepal Health research council,2004;2(2): 31-36.

[7]. T.Pramil, A Rajiv, G Gaurav. Pattern of prescribing at a paediatric outpatient setting in Northen India. Indian journal of Pharmacy practice, $2012 ; 5(1): 40-44$.

[8]. Dr.M.Ipp. Reduced antibiotic use in a paeditric practice: Practical office strategies based on current evidence. Published in June2000.

[9]. ShankerRV, Praveen Partha, Nagesh Kumar Shenoy, Joshy Maducolil Easow, Kottallur Narayanan Brahmadathan. Prescribing patterns of antibiotics and sensitivity patterns of common microorganisms in the Internal Medicine ward of a teaching hospital in Western Nepal: A prospective study. Annals of clinical Microbiology and Antimicrobials,2003;2:7-18.

[10]. Kafle KK. Pradhan YMS, Shrestha AD and Karki SB. Drug use in PHC facilities of Kathmandu. Journal of the institute of medicine, 1992; 14:318-26.

[11]. D K Choudhury, B K Bezbaruah. Antibiotic prescriptions pattern in Paediatric In-patient department Guwahati medical college and hospital, Guwahati. Journal of Applied pharmaceutical science, 2013;3(8):144-148.

[12]. Kanish Ravika, Gupta Kanchan, Juneja Shivani, Bains HS, Kaushal Sandeep. Prescribing pattern of antibiotics in the department of paediatrics in tertiary care medical college hospital in Northern India. Asian Journal of medical sciences, 2014;5(4):69-72.

[13]. Arute JE, Adigom DO, Erach PO, Eichie EF, Eniojukan JF. Antibiotic prescription pattern in the paediatric ward of a tertiary health care facility in southern Nigeria. Journal of Pharmaceutical and allied sciences,2011;8(3):34-42.

[14]. Triruthopu NS, Mateti UV, Bariri R, Sivva D, Marthas. Drug utilization pattern in south Indian paediatric population: A prospective study. Perspect Clin Res,2014;51:78-83

[15]. WHO. How to investigate drug use in health facilities: selected drug use indicators, Geneva: world health organization2010:WHO/DAP/93.

[16]. Shankar PR, Upadhyay DK, Subish P, Dubey AK, Mishra P. Prescribing patterns among paediatric in-patients in a teaching hospital in Western Nepal. Singapore Med J,2006;47(4):261-5.

[17]. Van Houten MA, Luinge K, Lasuer M, Kimpen JL. Antibiotic utilization for hospitalized paediatric patients. Internal J of antimicroagents, 1998; 10:161-4.

[18]. Leung Emily, Weil E Diana, Raviglione Mario, Nakatani Hiroki. The WHO policy package to combat antimicrobial resistance. Bulletin of the WHO 2011;89:390-392.

[19]. WHO model list of essential medicines, $4^{\text {th }}$ list, 2013(April): 8-16. www.who.int/medicines/publications/essentialmedicines/en.

[20]. Baktygul Kamba Ralieva, Marat Bozgunchiev, Ashirali Z, Harun MD, Sakamoto J. An assessment of antibiotics prescribed at the secondary health care level in the Kyrgyz Republic. Nagoya J Med Science, 2011; 73:157-168. 